\title{
Does Metabolic Rate Increase Linearly with Running Speed in all Distance Runners?
}

\section{(ㄷ) (1) $(\mathrm{)})$}

\author{
Authors \\ Matthew E. Batliner ${ }^{1}$, Shalaya Kipp ${ }^{1}$, Alena M. Grabowski', 2, Rodger Kram¹, William C. Byrnes ${ }^{1}$
}

Affiliations

1 University of Colorado Boulder, Department of Integrative Physiology, Boulder, United States

2 VA Eastern Colorado Healthcare System, Denver, United States

\section{Key words}

running economy, cost of transport, running energetics

$\begin{array}{ll}\text { received } & 06.07 .2017 \\ \text { revised } & 17.09 .2017 \\ \text { accepted } & 01.10 .2017\end{array}$

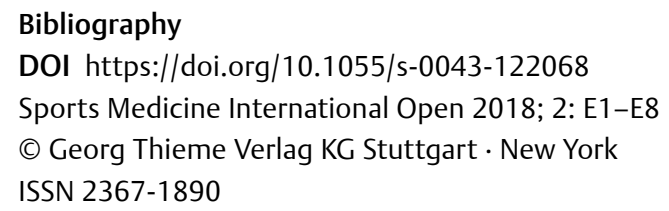

\section{Correspondence}

Prof. William C. Byrnes, PhD

University of Colorado Boulder

Department of Integrative Physiology

354UCB, Boulder, 80309-0354

United States

Tel.: + 1/303/492 5301, Fax: + 1/303/492 4009

byrnes@colorado.edu

\begin{abstract}
Running economy (oxygen uptake or metabolic rate for running at a submaximal speed) is one of the key determinants of distance running performance. Previous studies reported linear relationships between oxygen uptake or metabolic rate and speed, and an invariant cost of transport across speed. We quantified oxygen uptake, metabolic rate, and cost of transport in 10 average and 10 sub-elite runners. We increased treadmill speed by $0.45 \mathrm{~m} \cdot \mathrm{s}^{-1}$ from $1.78 \mathrm{~m} \cdot \mathrm{s}^{-1}$ (day 1 ) and $2.01 \mathrm{~m} \cdot \mathrm{s}^{-1}$ (day 2 ) during each subsequent 4 -min stage until reaching a speed that elicited a rating of perceived exertion of 15 . Average runners' oxygen uptake and metabolic rate vs. speed relationships were best described by linear fits. In contrast, the subelite runners' relationships were best described by increasing curvilinear fits. For the sub-elites, oxygen cost of transport and energy cost of transport increased by $12.8 \%$ and $9.6 \%$, respectively, from 3.58 to $5.14 \mathrm{~m} \cdot \mathrm{s}^{-1}$. Our results indicate that it is not possible to accurately predict metabolic rates at race pace for sub-elite competitive runners from data collected at moderate submaximal running speeds $\left(2.68-3.58 \mathrm{~m} \cdot \mathrm{s}^{-1}\right)$. To do so, metabolic rate should be measured at speeds that approach competitive race pace and curvilinear fits should be used for extrapolation to race pace.
\end{abstract}

\section{Introduction}

Running economy (RE), the oxygen uptake or metabolic rate for running at a given submaximal speed, is one of the key determinants of distance running performance $[4,6,14,16,18]$. Understanding how RE changes with running speed is important for predicting performance of high-level runners and absolute energy expended. However, there is disagreement about the nature of the quantitative relationship between RE and submaximal speed. Most previous research has focused on a narrow range of running speeds $\left(\sim 2-4 \mathrm{~m} \cdot \mathrm{s}^{-1}\right)$ in average to good runners and found that oxygen uptake or metabolic rate $\left(\mathrm{VO}_{2}, \mathrm{mlO}_{2} \cdot \mathrm{kg}^{-1} \cdot \mathrm{min}^{-1}\right.$ or $\dot{\mathrm{E}}$, $\mathrm{kcal} \cdot \mathrm{kg}^{-1} \cdot \mathrm{min}^{-1}$ ) increases linearly with running speed $[13,14,23,25,26]$. One can also calculate the cost of transport (COT) or the amount of oxygen or energy needed to transport a kilogram of body mass a given distance forward $\left(\mathrm{O}_{2} \mathrm{COT}, \mathrm{mlO}_{2} \cdot \mathrm{kg}^{-1} \cdot \mathrm{km}^{-1}\right.$; ECOT, $\mathrm{kcal} \cdot \mathrm{kg}^{-1} \cdot \mathrm{km}^{-1}$ ) by dividing oxygen uptake or metabolic rate by running speed $[8,28,31,32]$. If the intercept is zero, a linear relationship between oxygen uptake or metabolic rate and running speed results in a COT that is independent of running speed $[13,23,25,26,28]$. However a positive intercept results in a decreasing COT with speed to some asymptotic value, whereas a negative intercept results in an increasing COT to some asymptotic value. Together, the idea of a linear relationship between oxygen uptake or metabolic rate and running speed, and an invariant COT define what we call the "traditional model" of running energetics. 
The traditional model of running energetics has been supported by numerous investigations $[8,23,30]$. These studies measured the metabolic rate for running across a moderate range of submaximal running speeds $\left(\sim 2-4 \mathrm{~m} \cdot \mathrm{s}^{-1}\right)$ in average to good runners. In contrast, studies at faster speeds $\left(>4.5 \mathrm{~m} \cdot \mathrm{s}^{-1}\right)$ in sub-elite to elite runners $[7,13,14,21,34,35]$ are not in agreement. Some studies report a linear relationship between metabolic rate and speed and thus a nearly invariant gross COT $[13,14,23,25,26]$, whereas others have found that gross COT increased at faster running speeds $[7,25,35], 36]$. Additionally no studies have compared average runners to sub-elite distance runners, and very few have looked at subelite runners at slow speeds. Given the lack of consensus and the importance of RE on distance running performance, a more comprehensive re-examination of the energetics of running is needed.

We sought to quantify the metabolic rate and COT of running in average and sub-elite distance runners over a wide range of submaximal running speeds from $1.78 \mathrm{~m} \cdot \mathrm{s}^{-1}(4 \mathrm{MPH})$ to the speed corresponding to each individual's lactate threshold. We hypothesized that the relationship between the oxygen uptake or metabolic rate and speed would best be described as linear for the average group and curvilinear for the sub-elite group.

\section{Methods}

This research protocol was reviewed and approved by the University of Colorado Institutional Review Board and was performed in accordance with the ethical standards outlined by Harriss and Atkinson [12]. All subjects gave written informed consent before participating.

\section{Subjects}

Twenty healthy male runners ( 10 average and 10 sub-elite) participated. We classified subjects based on Morgan et al. [28] ( Table 1). The average group ran at least three times per week and was capable of running $10 \mathrm{~km}$ in $40-60 \mathrm{~min}$. The sub-elite group was capable of running $10 \mathrm{~km}$ in less than $30 \mathrm{~min}$ at sea level, or less than $31 \mathrm{~min}$ at the local altitude $(\sim 1600 \mathrm{~m})$.

\section{Experimental procedures}

Subjects performed a series of trials on either a custom-made [20] or Treadmetrix (Park City, UT, USA) motorized force-measuring treadmill. Three subjects completed the protocol on the custommade force treadmill before the axle of the non-drive roller failed. We then finished data collection on the Treadmetrix. Because both treadmills have rigid decks, there is no reason to expect differences in RE between the two treadmills. We used the same hand-held tachometer to verify running speed (Shimpo DT-107A, Electromatic Equipment Inc., Cedarhurst, NY, USA) on both treadmills. Subjects arrived to the laboratory $2 \mathrm{~h}$ post-prandial to help control for potential effects of diet on metabolic rate. During the experimental trials, we measured rates of oxygen uptake and carbon dioxide production to calculate metabolic rate using the caloric equivalents [11] determined from the respiratory exchange ratios (RER) with a widely accepted open circuit indirect calorimetry system (Parvomedics TrueOne 2400, Sandy, UT, USA) [5] . We calibrated the expired gas analysis system before each testing session using gas fractions calibrated with room air and a primary standard gas mixture within the physiological range $\left(16.01 \% \mathrm{O}_{2}\right.$ and $\left.4.01 \% \mathrm{CO}_{2}\right)$. We used a $3 \mathrm{~L}$ syringe at five distinct flow rates within the expected range of the study protocol to calibrate flow. We considered calibration complete when recorded volumes were within $1 \%$ of the calibration volumes, and gas fractions were within $0.3 \%$ of calibration values (e. g., $20.93 \pm 0.06 \%$ ).

The study took place over two days to minimize potential effects of fatigue from multiple trials. Day 1 trials began at $1.78 \mathrm{~m} \cdot \mathrm{s}^{-1}(4$ $\mathrm{MPH}$ ) and day 2 trials began at $2.01 \mathrm{~m} \cdot \mathrm{s}^{-1}(4.5 \mathrm{MPH})$. Subjects ran for $4 \mathrm{~min}$ at each speed. We increased treadmill speed by $0.45 \mathrm{~m} \cdot \mathrm{s}^{-1}(1 \mathrm{MPH})$ in each subsequent stage during both days. During the final minute of each 4-min stage, we asked subjects to provide a rating of perceived exertion (RPE) on the Borg (6-20) scale [9], until they reached an RPE of 15 (speed at RPE of $15=$ sRPE15) on both days. Previous data have demonstrated that an RPE value of 16 represents an intensity that corresponds closely to LT [22]. After the completion of each 4-min stage, we took a finger-prick blood sample to determine blood [La] and analyzed blood samples in duplicate with a YSI 2300 lactate analyzer (YSI, Yellow Springs, OH, USA). We monitored blood lactate concentrations [La] to assure a primary reliance on oxidative metabolism ([La] below lactate threshold, LT). We determined LT using the 1-mmolabove-baseline method described by Coyle et al. [4]. For subjects in our protocol this resulted in lactate values for all measured speeds under 2 to $3 \mathrm{mmol} \mathrm{I}^{-1}$.

Following the second session, subjects took a 10-min break and then completed a $\dot{V O}_{2 \max }$ test. Subjects ran at their SRPE15 on a level grade for two minutes. Then, we increased the grade by $1 \%$ each minute until exhaustion. $\dot{\mathrm{V}} \mathrm{O}_{2 \max }$ was defined as the greatest 15 -s mean value obtained. Our criteria for reaching $\dot{\mathrm{V}}_{2 \max }$ required a plateau in oxygen consumption (i. e., an increase in treadmill grade with no increase in oxygen consumption) and/or a respiratory exchange ratio (RER) over 1.15 [15]. All of our subjects reached $\dot{\mathrm{V}}_{2 \max }$ criteria.

\section{Data analyses/statistics}

We performed descriptive statistical analyses to determine means and standard deviations (SD) for average and sub-elite groups. We fit individual subjects' linear and $2^{\text {nd }}$-order curvilinear regressions to the $\dot{\mathrm{V}}_{2}$ and $\dot{E}$ values. $\mathrm{R}^{2}$ values for each subject were used to assess the strength of fit for both regression methods. We used a paired samples t-test to compare the means of individual $R^{2}$ values for linear and curvilinear fits. A linear-mixed model was used to determine main effects of speed and group classification on mean $\mathrm{O}_{2} \mathrm{COT}$, and ECOT. We used this model to compare each of these variables across speed to values obtained at the fastest submaximal speed achieved in each group. All statistical analyses were done using RStudio software (version 0.99.892, Boston, MA, USA).

\section{Results}

All average subjects completed stages up to a speed of $3.58 \mathrm{~m} \cdot \mathrm{s}^{-1}$ (9 stages) whereas all sub-elite subjects completed stages up to a speed of $5.14 \mathrm{~m} \cdot \mathrm{s}^{-1}$ (16 stages) before reaching sRPE15. Importantly, a comparison of the individual regression equations revealed no differences between days ( $p>0.05)$. 
- Table 1 Subject Characteristics.

\begin{tabular}{|c|c|c|c|c|c|}
\hline & Subject & Age (years) & 10 km Time (min) & $\left(\mathrm{mlO}_{2} \cdot \mathrm{kg}^{-1} \cdot \mathrm{min}^{-1}\right)$ & sRPE15 (meters $\mathrm{s}^{-1}$ ) \\
\hline \multirow[t]{11}{*}{ Average } & 1 & 23 & 45.5 & 55.1 & 4.70 \\
\hline & 2 & 23 & 48.0 & 48.7 & 4.25 \\
\hline & 3 & 24 & 44.5 & 57.9 & 4.25 \\
\hline & 4 & 30 & 46.3 & 61.9 & 4.25 \\
\hline & 5 & 25 & 49.0 & 52.7 & 3.80 \\
\hline & 6 & 27 & 44.4 & 59.8 & 4.25 \\
\hline & 7 & 27 & 46.0 & 54.0 & 3.80 \\
\hline & 8 & 25 & 44.0 & 55.9 & 4.02 \\
\hline & 9 & 30 & 52.0 & 44.7 & 3.58 \\
\hline & 10 & 28 & 41.0 & 56.6 & 4.02 \\
\hline & Mean \pm SD & $26.2 \pm 2.6$ & $46.1 \pm 3.0^{*}$ & $54.7 \pm 5.1^{*}$ & $4.09 \pm 0.32 *$ \\
\hline \multirow[t]{11}{*}{ Sub-elite } & 11 & 21 & $30.7^{\wedge}$ & 72.1 & 5.14 \\
\hline & 12 & 24 & 29.0 & 78.8 & 5.14 \\
\hline & 13 & 28 & $30.5^{\wedge}$ & 59.9 & 5.14 \\
\hline & 14 & 24 & 29.1 & 83.8 & 5.59 \\
\hline & 15 & 25 & 29.0 & 76.8 & 5.36 \\
\hline & 16 & 26 & $30.8^{\wedge}$ & 71.3 & 5.14 \\
\hline & 17 & 28 & 29.85 & 66.0 & 5.36 \\
\hline & 18 & 23 & 29.25 & 70.2 & 5.36 \\
\hline & 19 & 32 & $30.8^{\wedge}$ & 67.6 & 5.14 \\
\hline & 20 & 28 & 29.9 & 68.2 & 5.14 \\
\hline & Mean \pm SD & $25.9 \pm 3.2$ & $29.89 \pm 0.8^{*}$ & $71.47 \pm 6.9^{*}$ & $5.25 \pm 0.16^{*}$ \\
\hline
\end{tabular}

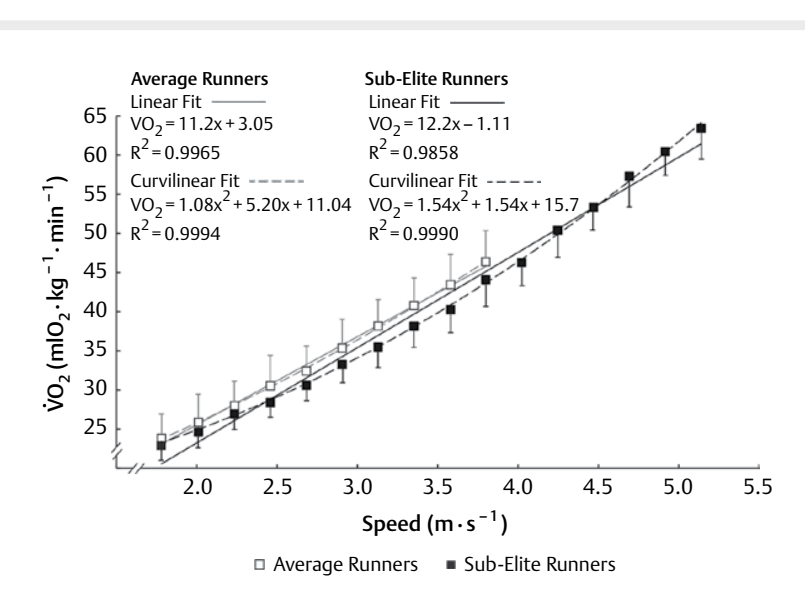

- Fig. $1 \dot{\mathrm{V}} \mathrm{2max}_{\max }$ vs. running speed for average and sub-elite subjects calculated from mean slopes, intercepts, quadratic coefficients, linear coefficients, and $R^{2}$ values for linear and curvilinear ( $2^{\text {nd }}$ order polynomial) fits. Data are presented up to the sRPE15 completed by all subjects in each group.

Oxygen uptake and metabolic rates were greater in the average group compared to the sub-elite group over comparable speeds $\left(1.78-3.58 \mathrm{~m} \cdot \mathrm{s}^{-1}\right)(\mathrm{p}<0.01)$ ( Fig. 1-3). The $\mathrm{R}^{2}$ values for each average subject's linear and curvilinear fits for $\dot{\mathrm{V}}_{2}$ and $\dot{\mathrm{E}} \mathrm{vs}$. speed were not different $(p>0.05)$, but were different for the sub-elite subjects $(\mathrm{p}<0.05)(\triangleright$ Tables 2 and $\triangleright \mathbf{3})$.

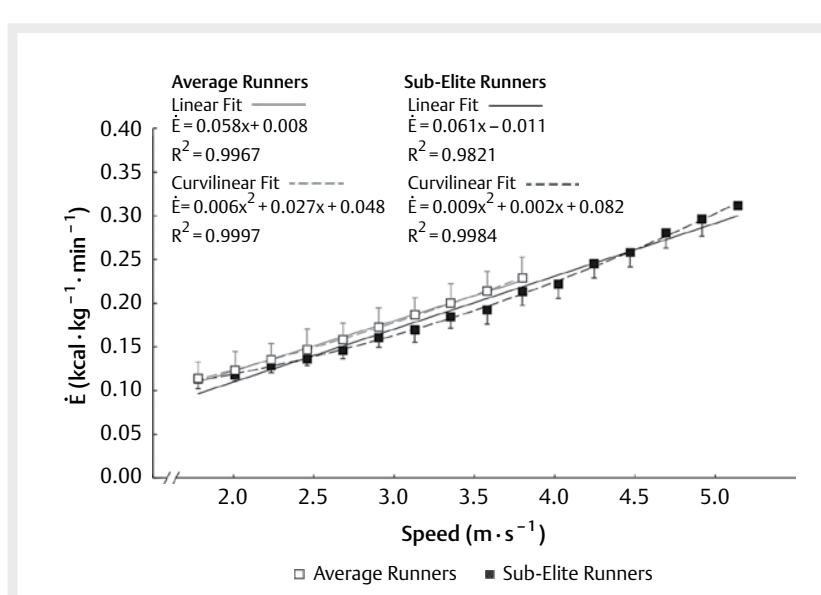

Fig. 2. Ė vs. running speed for average and sub-elite groups calculated from mean slopes, intercepts, quadratic coefficients, linear coefficients, and $R^{2}$ values for linear and curvilinear ( $2^{\text {nd }}$ order polynomial) fits. Data are presented up to the sRPE15 completed by all subjects in each group. Equivalent equations for predicting metabolic rate in watts/kilogram (W/kg): average linear, $\mathrm{W} /$ $\mathrm{kg}=4.0288 \mathrm{x}+0.5230$; average curvilinear, $\mathrm{W} / \mathrm{kg}=0.4185 \mathrm{x}^{2}+1.8833$ $\mathrm{x}+3.3480$; sub-elite linear, $\mathrm{W} / \mathrm{kg}=4.2548 \mathrm{x}-0.7882$; sub-elite curvilinear, $\mathrm{W} / \mathrm{kg}=0.5929 \mathrm{x}^{2}+0.1186+5.6986$

For the average group, $\mathrm{O}_{2} \mathrm{COT}$ and ECOT decreased by $10.2 \%$ and $7.9 \%$ respectively from speeds of 1.78 to $2.68 \mathrm{~m} \cdot \mathrm{s}^{-1}$, but did not change over the moderate running speed range of $2.68-$ 


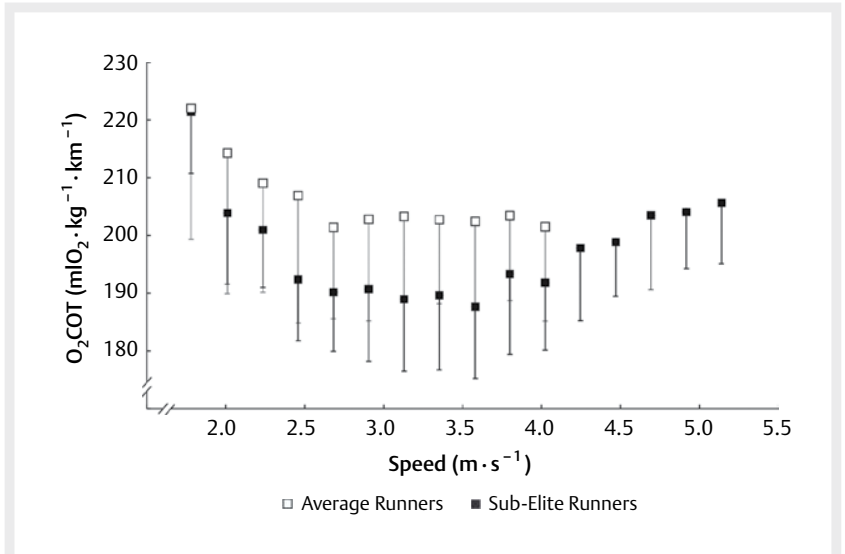

Fig. 3. Mean $\mathrm{O}_{2} \mathrm{COT}\left(\mathrm{mlO}_{2} \cdot \mathrm{kg}^{-1} \cdot \mathrm{km}^{-1}\right)$ values at each measured speed for average and sub-elite groups.

$3.58 \mathrm{~m} \cdot \mathrm{s}^{-1}$. In the sub-elite group, $\mathrm{O}_{2}$ COT and ECOT decreased by $14.1 \%$ and $14.4 \%$, respectively, from speeds of 1.78 to $2.68 \mathrm{~m} \cdot \mathrm{s}^{-1}$ and did not change over the moderate running speed range of 2.68 to $3.58 \mathrm{~m} \cdot \mathrm{s}^{-1}$ ( Fig. 3). However, the sub-elite group's $\mathrm{O}_{2} \mathrm{COT}$ and ECOT increased at faster running speeds. For example, $\mathrm{O}_{2} \mathrm{COT}$ and ECOT at $5.14 \mathrm{~m} \cdot \mathrm{s}^{-1}$, the fastest submaximal speed achieved by all sub-elite subjects, were $7.9-9.6 \%$ and $9.6-12.8 \%$ greater than $\mathrm{O}_{2} \mathrm{COT}$ and ECOT across the moderate speed range from 2.46 to $4.02 \mathrm{~m} \cdot \mathrm{s}^{-1}(\mathrm{p}<0.05)$.

\section{Discussion}

We accept our hypothesis that the relationships between oxygen uptake and metabolic rate ( $\left(\dot{\mathrm{V}} \mathrm{O}_{2}\right.$ and $\left.\dot{\mathrm{E}}\right)$ and speed are linear for the average runners, and curvilinear for sub-elite runners.

\section{Average group}

In accordance with the traditional model of running energetics, our average runners sustained only a moderate range of submaximal running speeds (mean speed range: $1.78-4.08 \mathrm{~m} \cdot \mathrm{s}^{-1}$ ). This population is not capable of maintaining steady-state oxygen consumption at faster running speeds because these speeds would correspond to intensities greater than LT [1,2]. Over the range of submaximal speeds achieved, the average group demonstrated equally strong linear and curvilinear fits characterizing oxygen uptake or metabolic rate and speed.

We found that the average group's COT was elevated at slow running speeds $\left(1.78-2.46 \mathrm{~m} \cdot \mathrm{s}^{-1}\right)$ compared to moderate running speeds. It should be noted that oxygen uptake and metabolic rate for running at these slow speeds is rarely reported. Over the more typically measured moderate speed range of $2.68-3.58 \mathrm{~m} \cdot \mathrm{s}^{-1}$, we found that the gross COT was independent of running speed, similar to previous studies [14, 23, 25, 26].

\section{Sub-elite Group}

As expected, sub-elite runners sustained faster submaximal running speeds than average runners, which allowed us to measure the oxygen uptake and metabolic rate over a wider range of speeds (mean speed range: $1.78-5.23 \mathrm{~m} \cdot \mathrm{s}^{-1}$ ). The majority of previous investigations of sub-elite to elite runners report linear relationships between metabolic rate and running speed over narrow speed ranges $[7,13,14,21]$. Over the wider range of speeds sustained by all sub-elite subjects $\left(1.78-5.14 \mathrm{~m} \cdot \mathrm{s}^{-1}\right)$, the oxygen uptake and metabolic rate vs. speed relationships were best described by curvilinear fits. Our data are in agreement with the findings of SteudelNumbers and Wall-Scheffler [35], who reported a curvilinear relationship between these variables over a similar wide range of speeds $\left(\sim 2.01-4.91 \mathrm{~m} \cdot \mathrm{s}^{-1}\right)$.

We found that the sub-elite group's COT was greater at both slow and fast running speeds than at moderate running speeds. Although this finding contradicts the traditional model of running energetics, it is not unprecedented. For example, when we converted Daniels and Daniels [7] $\mathrm{VO}_{2}$ data for elite marathon runners (4.83$6.17 \mathrm{~m} \cdot \mathrm{s}^{-1}$ ) to $\mathrm{O}_{2} \mathrm{COT}$, we calculated a $\sim 9 \%$ increase in $\mathrm{O}_{2} \mathrm{COT}$ at 6.17 compared to $4.83 \mathrm{~m} \cdot \mathrm{s}^{-1}\left(180-197 \mathrm{mlO}_{2} \cdot \mathrm{kg}^{-1} \cdot \mathrm{km}^{-1}\right)$. Our data are also consistent with Tam et al. [35] who reported significant increases in $\mathrm{O}_{2} \mathrm{COT}$ at $5.0 \mathrm{~m} \cdot \mathrm{s}^{-1}$ compared to $3.33 \mathrm{~m} \cdot \mathrm{s}^{-1}$ in elite distance runners. Tam et al. suggested that this finding could be explained by the increasing contribution of aerodynamic resistance to the metabolic rate during their over-ground running protocol. However, this does not explain our findings or those of Daniels and Daniels [7], because treadmill running involves negligible aerodynamic resistance. Pugh [29] compared track and treadmill running to estimate the energy cost of overcoming air resistance. Two of his four subjects inexplicably had a non-linear relationship between speed and $\dot{\mathrm{VO}}_{2}$ on the treadmill. Our data also support the findings of Mayhew [24] as well as Steudel-Numbers and WallScheffler [35], who reported increases in $\mathrm{O}_{2}$ COT and ECOT at slow and fast running speeds compared to moderate speeds in runners during treadmill running over similar speed ranges ( $2.33-$ $4.67 \mathrm{~m} \cdot \mathrm{s}^{-1}$ and $\left.\sim 2.01-4.9 \mathrm{~m} \cdot \mathrm{s}^{-1}\right)$. Thus, the traditional model of running energetics seems appropriate for a narrow range of moderate running speeds $\left(2.68-3.58 \mathrm{~m} \cdot \mathrm{s}^{-1}\right)$, but not slower $\left(<2.68 \mathrm{~m} \cdot \mathrm{s}^{-1}\right)$ or faster speeds $\left(>3.58 \mathrm{~m} \cdot \mathrm{s}^{-1}\right)$. The cost of generating force hypothesis appears to explain the near constant COT for moderate speeds [30]. At very slow running speeds with slow stride frequencies, the spring-mass model for running may not be valid [10]. At faster running speeds, it appears that running adopts more flexed leg postures, which reduce the mechanical advantage that requires recruitment of more muscle volume [3].

\section{Implications for performance predictions}

Traditionally, it has been thought that the oxygen uptake and metabolic rate for competitive runners can be calculated from the COT measured at any submaximal running speed or predicted from linear extrapolation of the oxygen uptake or metabolic rate vs. speed relationship [13]. Velocity at $\dot{\mathrm{V}} \mathrm{O}_{2 \max }\left(\mathrm{v} \dot{\mathrm{V}} \mathrm{O}_{2 \max }\right)$ is commonly determined from a linear extrapolation of the oxygen uptake or metabolic rate vs. speed relationship up to $\dot{\mathrm{V}} \mathrm{Z}_{2 \max }[6,8,27]$. The traditional model of running energetics implies that linear extrapolation of submaximal running speeds is an appropriate method for estimating the metabolic rate at all speeds [8, 16, 27]. However, our finding of a curvilinear relationship between oxygen uptake or metabolic rate and speed demonstrates that this assumption is not always valid. In our sub-elite group, $v \mathrm{~V}_{2 \max }$ calculated from linear 


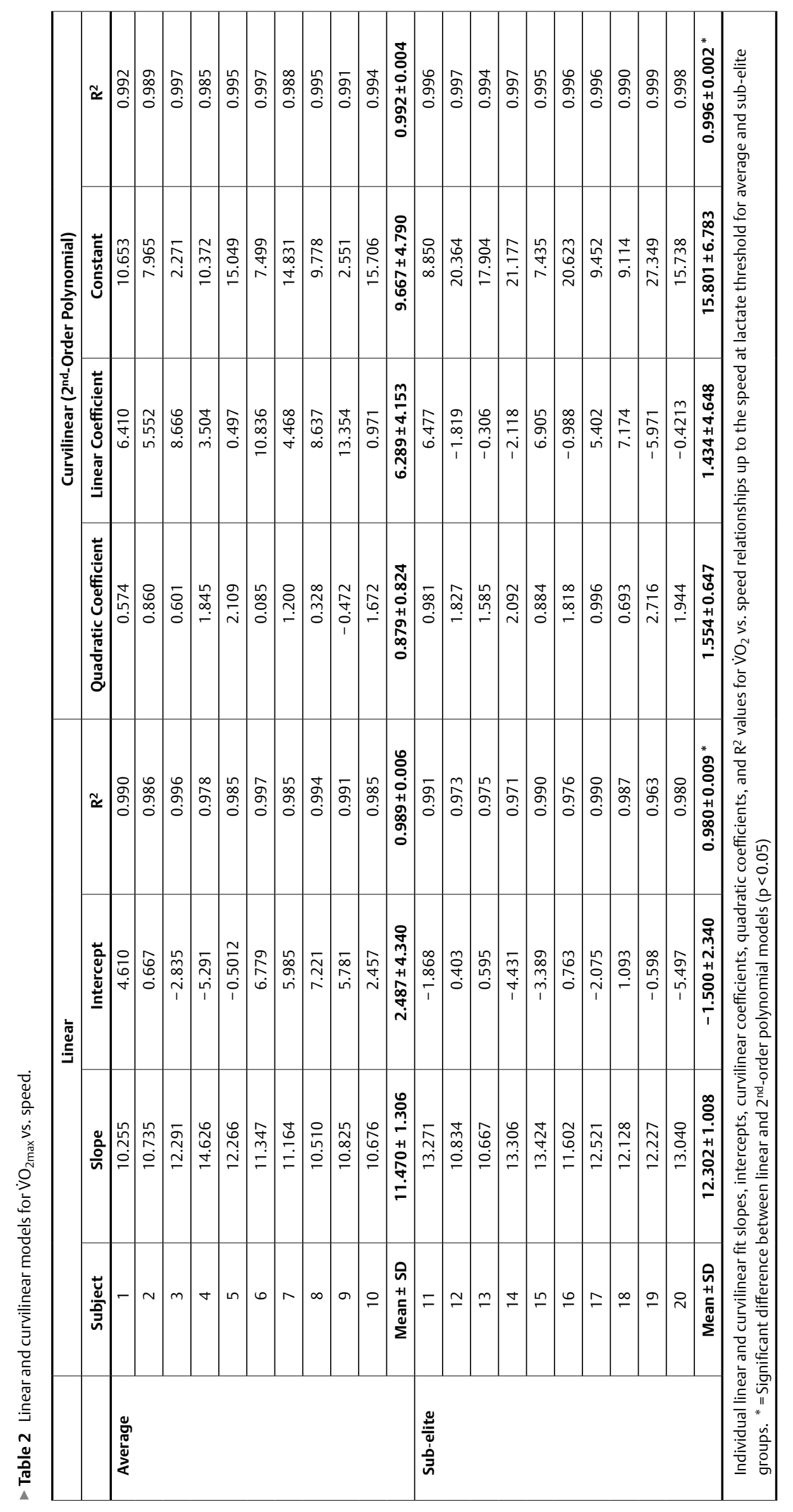




\begin{tabular}{|c|c|c|c|c|c|c|c|c|c|c|c|c|c|c|c|c|}
\hline & $\approx$ & 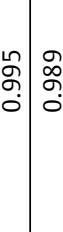 & 各 & 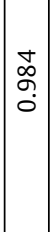 & 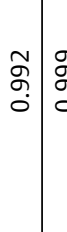 & 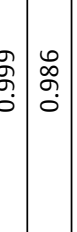 & 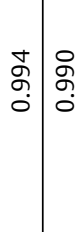 & $\begin{array}{l} \\
\\
\infty \\
\infty \\
o \\
o \\
0 \\
0\end{array}$ & 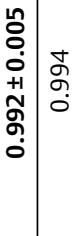 & 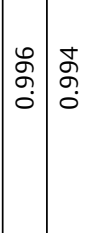 & \begin{tabular}{|l|l} 
& \multicolumn{2}{|c}{} \\
O. \\
0
\end{tabular} & นू & 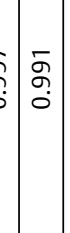 & 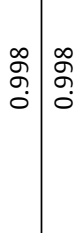 & 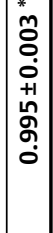 & 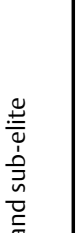 \\
\hline 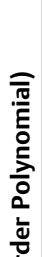 & 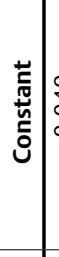 & 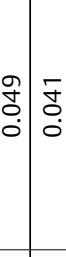 & $\begin{array}{l}\infty \\
\vdots \\
0 \\
0\end{array}$ & $\begin{array}{l}\bar{f} \\
\dot{d} \\
\dot{0}\end{array}$ & 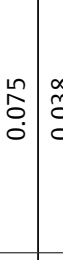 & \begin{tabular}{l|l|}
$\infty$ & 0 \\
0 & 0 \\
0 & 0 \\
0 & 0 \\
&
\end{tabular} & 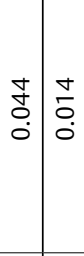 & $\begin{array}{l} \\
\text { 오 } \\
\hat{0} \\
\dot{0} \\
0\end{array}$ & \begin{tabular}{l|l}
$\overline{\mathbf{s}}$ & \\
$\dot{0}$ & 8 \\
+1 & 8 \\
0 & 0 \\
$\dot{0}$ & 0 \\
$\dot{0}$ &
\end{tabular} & \begin{tabular}{|l|l}
$\approx$ & 0 \\
0 & 0 \\
0 & 0 \\
0 & 0 \\
& 0
\end{tabular} & \begin{tabular}{|c|c|c}
1 & 0 \\
\hdashline & 0 \\
0 & 0 \\
0
\end{tabular} & $\frac{0}{0}$ & 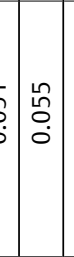 & \begin{tabular}{c|c|c}
$\stackrel{m}{\sim}$ & $\stackrel{m}{\circ}$ & $\stackrel{0}{0}$ \\
0
\end{tabular} & 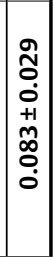 & 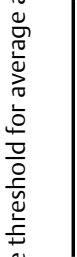 \\
\hline 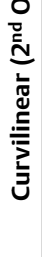 & 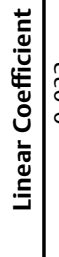 & 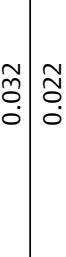 & $\begin{array}{l}n \\
\tilde{o} \\
\dot{0}\end{array}$ & $\mid \begin{array}{l}0 \\
\tilde{\sigma} \\
\dot{0}\end{array}$ & 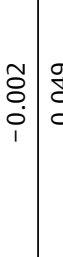 & 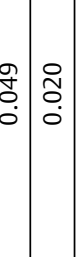 & 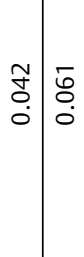 & 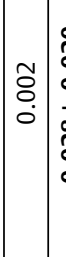 & 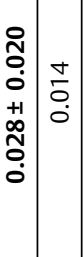 & \begin{tabular}{l|l} 
& \\
$\bar{\sigma}$ & 0 \\
0 & 0 \\
0 & 0 \\
1 & 0
\end{tabular} & 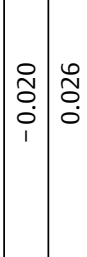 & $\begin{array}{cc}0 & 0 \\
0 & 0 \\
0 \\
i \\
i\end{array}$ & 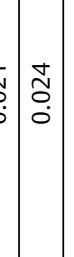 & \begin{tabular}{l|l}
$m$ & 0 \\
$\hat{0}$ & 8 \\
0 & 0 \\
$i$ & $i$ \\
$i$
\end{tabular} & 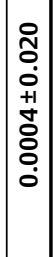 & 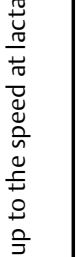 \\
\hline & 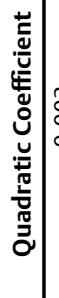 & $\begin{array}{l} \\
\\
\stackrel{m}{0} \\
\dot{0} \\
\end{array}$ & 号 & $\begin{array}{l}8 \\
\dot{0} \\
\dot{0}\end{array}$ & \begin{tabular}{l|l}
$\pi$ & \\
0 & \\
0 & \\
0
\end{tabular} & \begin{tabular}{l|l|l}
$\bar{\delta}$ & $\overline{0}$ \\
$\vdots$ & 0 \\
0 & 0 \\
0
\end{tabular} & \begin{tabular}{l|l}
$\tilde{o}$ & $\overline{8}$ \\
0 & 0 \\
0 & \\
\end{tabular} & 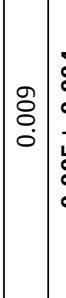 & \begin{tabular}{l|l}
$\dot{d}$ & \\
$\dot{0}$ & $\infty$ \\
0 & 0 \\
+1 & 0 \\
& 0 \\
0 & \\
$\dot{0}$ &
\end{tabular} & 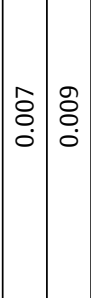 & \begin{tabular}{|l|l}
$\overline{0}$ & $\stackrel{0}{0}$ \\
0 & 0 \\
0
\end{tabular} & $\begin{array}{ll}0 & 0 \\
0 & 0 \\
0 & 0 \\
0\end{array}$ & 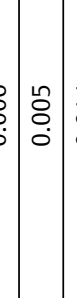 & \begin{tabular}{l|l}
$\begin{array}{l}\sigma \\
\vdots\end{array}$ & $\overline{0}$ \\
0 & 0 \\
$\dot{0}$
\end{tabular} & 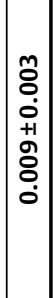 & 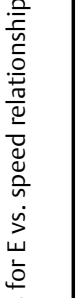 \\
\hline & $\approx$ & 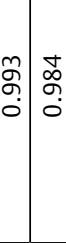 & 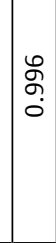 & $\mid \begin{array}{l}\hat{1} \\
\hat{\sigma} \\
0\end{array}$ & 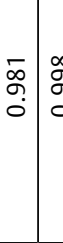 & 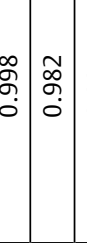 & 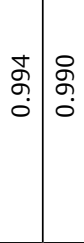 & 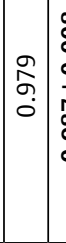 & 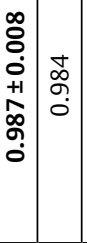 & 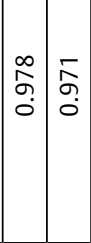 & 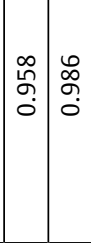 & $\mid$\begin{tabular}{l|l}
$\mathbb{N}$ & 0 \\
$\vdots$ & 0 \\
0 & 0 \\
0
\end{tabular} & 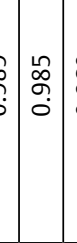 & 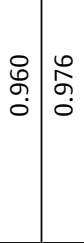 & $\begin{array}{l}* \\
\bar{c} \\
0 \\
\dot{0} \\
+1 \\
\hat{1} \\
\hat{\alpha} \\
0 \\
0\end{array}$ & 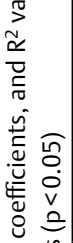 \\
\hline 总 & 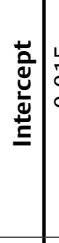 & $\begin{array}{l}n \\
\vdots \\
0 \\
0\end{array}$ & $\begin{array}{l}\bar{z} \\
\vdots \\
i \\
i\end{array}$ & $\mid \begin{array}{l}0 \\
\hat{0} \\
0 \\
i \\
1\end{array}$ & \begin{tabular}{cc}
$m$ & \multicolumn{1}{c}{} \\
0 & 0 \\
0 & 0
\end{tabular} & 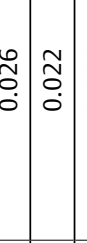 & 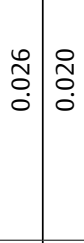 & : & 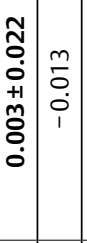 & \begin{tabular}{|c|c}
$\bar{\delta}$ & 0 \\
0 \\
0 \\
0 \\
0 \\
0
\end{tabular} & 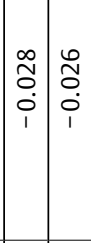 & $\begin{array}{ll}T & 0 \\
0 & 0 \\
0 & 0 \\
i & 0 \\
1\end{array}$ & $\begin{array}{l}0 \\
\vdots \\
\vdots \\
0 \\
0 \\
0 \\
1\end{array}$ & 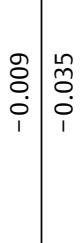 & $\begin{array}{c}\mathbf{N} \\
\mathbf{0} \\
0 \\
+1 \\
+1 \\
\vdots \\
0 \\
0 \\
1\end{array}$ & 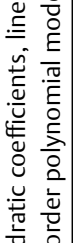 \\
\hline & $\begin{array}{l}0 \\
\vdots \\
\overline{0}\end{array}$ & 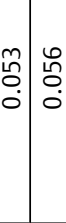 & $\begin{array}{l}n \\
\mathscr{o} \\
0\end{array}$ & $\begin{array}{l}n \\
0 \\
0 \\
0\end{array}$ & \begin{tabular}{l|l}
$n$ \\
0 \\
0 \\
0 & \\
0 & \\
0
\end{tabular} & 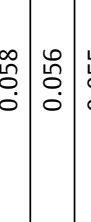 & 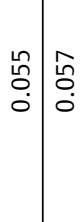 & 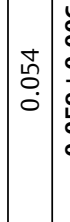 & 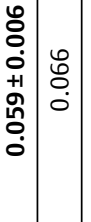 & 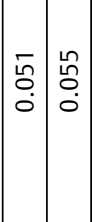 & \begin{tabular}{|l|l}
$\qquad$ & 0 \\
0 & 0 \\
0 & 0 \\
0 & 0
\end{tabular} & $\begin{array}{lll}\infty & 0 \\
0 & 0 \\
0 & 0 \\
0 & 0\end{array}$ & 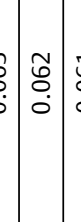 & 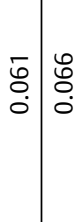 & $\mid \begin{array}{l}0 \\
0 \\
0 \\
+1 \\
\dot{+1} \\
\dot{0} \\
0 \\
0\end{array}$ & 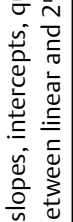 \\
\hline & 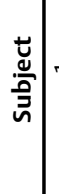 & - & $m$ & $\nabla$ & & 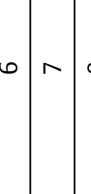 & \begin{tabular}{l|l}
$\infty$ & $\sigma$
\end{tabular} & $\circ$ & 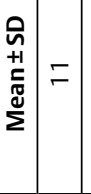 & $\simeq \stackrel{m}{=}$ & \begin{tabular}{l|l} 
\pm & $\stackrel{\Perp}{\sim}$
\end{tabular} & 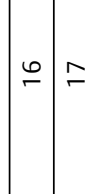 & $=\stackrel{\infty}{-}$ & $\stackrel{\sim}{\longrightarrow}$ & 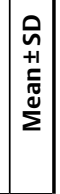 & 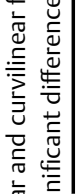 \\
\hline & & 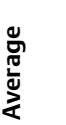 & & & & & & & 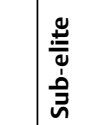 & & & & & & & 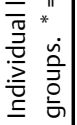 \\
\hline
\end{tabular}


extrapolation of data collected at a series of moderate speeds ranging from $2.68-3.58 \mathrm{~m} \cdot \mathrm{s}^{-1}$, averaged $0.80 \mathrm{~m} \cdot \mathrm{s}^{-1}$ faster than for faster speeds ranging from 4.47 to $5.14 \mathrm{~m} \cdot \mathrm{s}^{-1}$ (6.45 vs. $\left.5.67 \mathrm{~m} \cdot \mathrm{s}^{-1}\right) \cdot \mathrm{vVO}_{2 \max }$ calculated using a linear extrapolation over a wider range of speeds from 2.68 to $5.14 \mathrm{~m} \cdot \mathrm{s}^{-1}$ (a range excluding slow running speeds) results in a nearly $0.33 \mathrm{~m} \cdot \mathrm{s}^{-1}$ faster $\mathrm{v} \dot{\mathrm{V}} \mathrm{O}_{2 \text { max }}$ than if calculated using a curvilinear extrapolation (5.45 vs. $\left.5.77 \mathrm{~m} \cdot \mathrm{s}^{-1}\right)$. Thus, $v \dot{\mathrm{V}} \mathrm{O}_{2 \max }$ values are often overestimated when calculated from linear extrapolation of moderate speed values. More valid estimates of sub-elite $\mathrm{v}_{\mathrm{V}} \mathrm{O}_{2 \max }$ can be obtained from linear extrapolation at a series of fast running speeds $\left(>4.47 \mathrm{~m} \cdot \mathrm{s}^{-1}\right)$ or a curvilinear extrapolation at a wider range of speeds.

Recent world record performances in the marathon have motivated predictions of the ultimate marathon performance from a variety of physiological parameters. Joyner et al. [19] argued that breaking the 2-h marathon will require exceptional running economy. Extrapolating the metabolic rate from our sub-elite runners at 2-h marathon pace demonstrates that a curvilinear extrapolation results in a $15 \%$ greater predicted metabolic rate compared to a linear extrapolation. Because this extrapolation is from treadmill running, this predicted difference would likely be greater for road racing due to the nonlinear relationship between air resistance and speed. Consequently, a sub-2-h marathon may be more difficult than previously appreciated.

\section{Limitations}

Competitive distance runners compete at speeds well above LT during a $10 \mathrm{~km}$ race. To our knowledge, it is not yet clear whether, or how, the total metabolic rate (both oxidative and non-oxidative) of running changes at these intensities $[2,17]$. We intentionally did not examine the metabolic rate for running at speeds corresponding to intensities greater than LT in order to ensure only oxidative metabolism. As a result, we were not able to quantify the metabolic rate for running at a competitive race pace. Further, we are not able to ensure that the relationships observed here will hold true up to race pace. Finally, we performed this investigation at a moderate altitude of $\sim 1600$ meters albeit with a subject population that was acclimatized to this environment.

\section{Future directions}

We have not yet elucidated the biomechanical and physiological basis for the relationships reported here. Previous investigations have demonstrated correlations between biomechanical parameters and the metabolic rate for running. Some correlates include ground contact time, vertical ground reaction force, elastic energy return, and vertical center of mass oscillation [33]. It is possible that changes in running mechanics may, in part, explain the curvilinear metabolic rate vs. running speed relationships that we observed.

\section{Conclusions}

We conclude that the traditional model of running energetics is appropriate only over a narrow range of moderate running speeds $\left(\sim 2.68-3.58 \mathrm{~m} \cdot \mathrm{s}^{-1}\right)$. Because average runners are capable of sustaining only a moderate range of submaximal running speeds, the traditional model of running energetics accurately describes the metabolic rate for running in these populations. However, this model significantly underestimates the ECOT at slower (speeds $<2.68 \mathrm{~m} \cdot \mathrm{s}^{-1}$ ) and faster speeds (speeds $>3.58 \mathrm{~m} \cdot \mathrm{s}^{-1}$ ) by up to $12.8 \%\left(5.14 \mathrm{~m} \cdot \mathrm{s}^{1}\right)$. In order to best model the relationship between metabolic rate and running speed of sub-elite competitive runners, we suggest that future investigations measure subjects' metabolic rate at a series of four to five fast running speeds that approach a runners' competitive race pace and use curvilinear fitting to best extrapolate the race pace.

\section{Acknowledgements}

This research was partially supported by an unrestricted gift from Saucony Inc. The views expressed are those of the authors and do not reflect those of Saucony Inc.

\section{Conflict of Interest}

The authors do not have any conflicts of interest to declare.

\section{References}

[1] Bangsbo J. Oxygen deficit: a measure of the anaerobic energy production during intense exercise? Can J Appl Physiol 1996; 21: 350-363

[2] Bickham D, Gibbons C, Le Rossignol P. 2004; $\mathrm{VO}_{2}$ is attenuated above the lactate threshold in endurance-trained runners. Med Sci Sports Exerc 2004; 36: 297-301

[3] Biewener AA, Farley CT, Roberts T], Temaner M. Muscle mechanical advantage of human walking and running: Implications for energy cost. J Appl Physiol 2004; 97: 2266-2274

[4] Coyle EF. Integration of the physiological factors determining endurance performance ability. Exerc Sports Sci Rev 1985; 23: 25-63

[5] Crouter SE, Antczak A, Hudak JR, DellaValle DM, Haas JD. Accuracy and reliability of the ParvoMedics TrueOne 2400 and MedGraphics VO2000 metabolic systems. Euro J Appl Physiol 2006; 98: 139-151

[6] Daniels J. A physiologist's view of running economy. Med Sci Sports Exerc 1985; 17: 332-338

[7] Daniels ], Daniels N. Running economy of elite male and elite female runners. Med Sci Sports Exerc 1992; 24: 483-489

[8] Di Prampero G, Atchou JC, Moia C. The energetics of endurance running. Eur J Appl Physiol 1986; 55: 259-266

[9] Eston R, Davies B, Williams J. Use of perceived effort ratings to control exercise intensity in young healthy adults. Eur J Appl Physiol 1987; 56 : 222-224

[10] Farley CT, Gonzalez O. Leg stiffness and stride frequency in human running. J Biomech 1996; 29: 181-186

[11] Fletcher J, Esau S, MacIntosh B. Economy of running: beyond the measurement of oxygen uptake. J Appl Physiol 2009; 107: 1918-1922

[12] Harriss DJ, Atkinson G. Ethical standards in sport and exercise science research: 2016 update. Int J Sports Med 2015; 36: 1121-1124

[13] Helgerud J, Storind O, Hoff J. Are there differences in economy at different velocities for well-trained distance runners? Eur J Appl Physiol 2009; 108: 1099-1105

[14] Helgerud J. Maximal oxygen uptake, anaerobic threshold and running economy in women and men with similar performance level in marathons. Eur J Appl Physiol 1994; 68: 155-161 
[15] Issekutz B, Birkhead NC, Rodahl K. Use of respiratory quotients in assessment of aerobic work capacity. J Appl Physiol 1962; 1: 47-50

[16] Jones A. The physiology of the world record holder for the women's marathon. Int J Sports Sci Coaching 2006; 1: 101-116

[17] Jones A, Grassi B, Christensen P, Krustup P, Bangsbo J, Poole D. Slow component of kinetics: mechanistic bases and practical applications. Med Sci Sports Exerc 2011; 43: 2046-2062

[18] Joyner M. Modeling: optimal marathon performance on the basis of physiological factors. J Appl Physiol 1991; 70: 683-687

[19] Joyner M, Ruiz J, Lucia A. The two hour marathon: who and when? J Appl Physiol 2011; 110: 275-277

[20] Kram R, Griffin M, Donelan J, Chan YH. Force treadmill for measuring vertical and horizontal ground reaction forces. J Appl Physiol 1998; 85: 764-769

[21] Lacour R, Padilla-Magunacelaya S, Barthelemy ], Dormois D. The energetics of middle-distance running. Eur J Appl Physiol 1990; 60: 38-43

[22] Lim AC, Peterman JE, Turner BM, Livingston LR, Byrnes WC. Comparison of male and female road cyclists under identical stage race conditions. Med Sci Sports Exerc 2011; 43: 846-852

[23] Margaria R, Cerretelli P, Aghemo P, Sassi G. Energy cost of running. J Appl Physiol 1963; 18: 367-370

[24] Mayhew J. Oxygen cost and energy expenditure of running in trained runners. Brit J Sports Med 1977; 11: 116-121

[25] McCardel W, Katch F, Katch V. Exercise Physiology: Energy, Nutrition, and Human Performance. 6th ed. New York: Lippincott Williams \& Wilkens; 2007: 208
[26] Menier D, Pugh L. The relation of oxygen intake and velocity of walking and running competition walkers. J Physiol 1968; 197: 717-721

[27] Morgan DW, Baldini F, Martin P, Kohrt W. Ten kilometer performance and predicted velocity at $\mathrm{VO} 2 \mathrm{max}$ among well-trained male runners. Med Sci Sports Exerc 1989; 21: 78-83

[28] Morgan DW, Bransford DR, Costill DL, Daniels JT, Howley ET, Krahenbuhl GS. Variation in the aerobic demand among trained and untrained subjects. Med Sci Sports Exerc 1995; 27: 404-409

[29] Pugh LGEE. Oxygen intake in the track and treadmill running with observations on the effect of air resistance. J Physiol 1970; 297: 823-835

[30] Roberts T, Kram R, Weyand P, Taylor CR. Energetics of bipedal running. I. Metabolic cost of generating force. J Exp Biol 1998; 201: 2745-2751

[31] Rubenson J, Heliams DB, Maloney SK, Withers PC, Lloyd DG, Fournier PA. Reappraisal of the comparative cost of human locomotion using gait specific analyses. J Exp Biol 2007; 210: 3513-3524

[32] Schmidt-Nielsen K. Locomotion: Energy cost of swimming, flying, and running. Science 1972; 177: 222-228

[33] Sanders P, Pyne D, Telford R, Hawley J. Factors affecting running economy in trained distance runners. Sports Med 2004; 34: 466-485

[34] Steudel-Numbers K, Wall-Scheffler C. Optimal running speed and the evolution of hominin hunting strategies. J Hum Evol 2009; 56: 355-360

[35] Tam E, Rossi H, Moia C, Beradelli C, Rosa G, Capelli C, Ferretti G. Energetics of running in top-level marathon runners from Kenya. Eur J Appl Physiol 2012; 112: 3797-3806 